\title{
Hair Analysis of Mammals of Brazilian Wildlife for Forensic Purposes
}

\section{Tália Missen Tremori ${ }^{*}$, Fernanda Marion Monteiro Garcia1, Luis Mauricio Montoya Flórez ${ }^{1}$, Bianca Picado Gonçalves², Bárbara Wagner Duarte Ferraz de Camargo', Claire Gwinnett ${ }^{3}$, Carlos Roberto Teixeira4 ${ }^{4}$, Noeme Sousa Rocha ${ }^{1}$}

\author{
${ }^{1}$ Department of Veterinary Clinics, School of Veterinary Medicine and Animal Science, Sao Paulo State University, Botucatu, \\ Brazil \\ ${ }^{2}$ Department of Genetics, Sao Paulo State University, Botucatu, Brazil \\ ${ }^{3}$ Faculty of Computing, Engineering and Sciences, University of Staffordshire, Staffordshire, UK \\ ${ }^{4}$ Department of Surgery and Anesthesiology, School of Veterinary Medicine and Animal Science, Sao Paulo State University, \\ Botucatu, Brazil \\ Email: *talia_missen@hotmail.com
}

How to cite this paper: Tremori, T.M., Garcia, F.M.M., Flórez, L.M.M., Gonçalves, B.P., de Camargo, B.W.D.F., Gwinnett, C., Teixeira, C.R. and Rocha, N.S. (2018) Hair Analysis of Mammals of Brazilian Wildlife for Forensic Purposes. Open Journal of Animal Sciences, 8, 335-345.

https://doi.org/10.4236/ojas.2018.83025

Received: June 21, 2018

Accepted: July 22, 2018

Published: July 25, 2018

Copyright $\odot 2018$ by authors and Scientific Research Publishing Inc. This work is licensed under the Creative Commons Attribution International License (CC BY 4.0).

http://creativecommons.org/licenses/by/4.0/

\begin{abstract}
Wildlife trafficking is classified as the fourth largest illegal commerce in the world. Taxonomic identification of wildlife is an ordinary process for forensics experts. The aim of this study was to analyze animal's hair from Brazilian's wildlife through microscopic and compare morphology of bristle among species analyzed. Hair samples of nine species were analyzed. Glass slides were analyzed through optical microscopy and following measurements were obtained: total length, medulla diameter, overall diameter and overall ratio diameter of the medulla's diameter. The images obtained at identification of animals through the morphology of hair and the statistics analysis corroborates in favor for the validation of the technique.
\end{abstract}

\section{Keywords}

Forensic Zoobiology, Hair Analysis, Veterinary Forensic Medicine, Animal Expertise, Animal Trafficking, Smuggling

\section{Introduction}

Brazil is a country of great importance for global biodiversity; there are 658 mammalian species whereas approximately $10 \%$ are considered as endangered. The loss of biodiversity is one of the greatest problems facing society today [1]. Due to major environmental disasters and a decrease in the number of species, this environmental issue has been highlighted in the scientific community, 
drawing the attention of the Public Power and the community about environmental protection. Approximately 82 species of mammals are in danger of extinction in Brazil [2] [3].

Wildlife trafficking is classified as the fourth biggest illegal commerce, behind firearms, drugs and people trafficking [1]. While the number of species in extinction increases, the effect is adverse: instead of reducing the traffic, the demand for these species has intensified due to its rarity. This has consequently increased the potential gain with its illegal practice [2].

Within Brazil's legislation, crimes against the environment belong to the Law on Environmental Crimes (Law 9605/98), this is a major advance among constitutional standards, turning Brazil into one of the most advanced countries regarding standards applied to environmental protection. However, great efforts are still needed to ensure that the sanctions are harshly applied [4].

Veterinary Forensic Medicine was created with the goal of combining knowledge of veterinary medicine with the law when assisting in environmental issues such as wildlife trafficking and animal abuse. Hence, this advances knowledge and skills in wildlife crime investigations, thereby sustaining the evidential value of evidence such as animal hairs and improving case investigations. Because of these benefits, the need for training further professionals in the area was seen [5] [6] [7].

The taxonomic identification of the wild fauna is an ordinary activity for the forensics expert in the area of veterinary medicine [8] [9]. The techniques currently available include the use of photodocumentation, zoobiology, forensic genetics and also identification through hair analysis. In addition to the knowledge of trichological information, the geographical distribution of the species should be taken into account for a more accurate identification. Identification is not always easy, considering that the samples found may be insufficient for certain types of tests [6] [10] [11]. With the investment in new techniques of species identification and the development of studies in the area of taxonomy, the number of identifications has increased [12] [13].

Hair identification has been reported by different techniques along two centuries, nowadays it is also used to the traces analyze crime scene's collected genetic samples and give other precious information like the presence of toxic agents, parasites, diseases and particular details from the crime scene [14] [15] [16] [17]. However morphologic and morph metric characteristics' examination based on microscopy, which may enable the hair analyst to identify hair as from animal origin [18], to characterize the hair to a particular species [19] [20], and to conduct comparative examinations [12].

The aim of this study is to outline the key features of animal hair retrieved from nine different species of Brazilian wild mammals that are commonly trafficked. This study will aid the identification of such species in wildlife crime investigations in Brazil and countries where products from these species are trafficked. 


\section{Methods}

Hair samples of nine animals from Brazilian fauna species were seized by the Environmental Military Police in illegal conditions, e.g. animal trafficking, smuggling, physical abuse among others mistreatments and designated to Laboratory of Forensic Veterinary Pathology of FMVZ-UNESP/Botucatu and Center of Medicine and Research of Wild Animals-CEMPAS during six months. This study was approved by Ethical Committee of Animal Use (CEUA-protocol 86/2015) and had authorization from SISBIO/IBAMA n ${ }^{\circ}$ 49607-2.

Hairs (20 - 30) were obtained from each animal using tweezers and pulled out from the region of the intersection of the median line with the waistline. Each sample was processed by two way using glass microscopic slides for medulla analysis.

Initially, the hairs with root bulb and tip, were separated from the others and washed with commercial ethyl alcohol and dried upon a paper towel.

The preparation for medulla analysis could be set up by two manners. Put on the whole hair between two glass microscopic slides and to attach the ends with adhesive tape. In addition, one layer of resin may be applied on glass microscopic slides and put on the whole length of the hair, an additional cover glass microscope slide was placed on top and then applied force with fingers.

If it is a medulla sample from pigmented hair, it should be in a whitening mixture composed of hydrogen peroxide and decolorizing powder (30\% for 80 minutes). The exposure time to the hydrogen peroxide varied depending on the thickness and size of the hair samples. The hairs were then mounted on a microscope slide and to avoid loss, secured using a small amount of adhesive tape at each end. The glass slides were labeled with species identification and stored in a microscope slide box [11].

Each hair was observed using a computerized image analyzer Axio Vision Rel 4.8, Carl Zeiss ${ }^{\circledR}$, German, high powered microscope at $\times 100, \times 200$ and $\times 400$ magnification, and photographs taken for comparison using the software Image J, SciJava ${ }^{\circledR}$, the following measurements were obtained (Figure 1) medulla

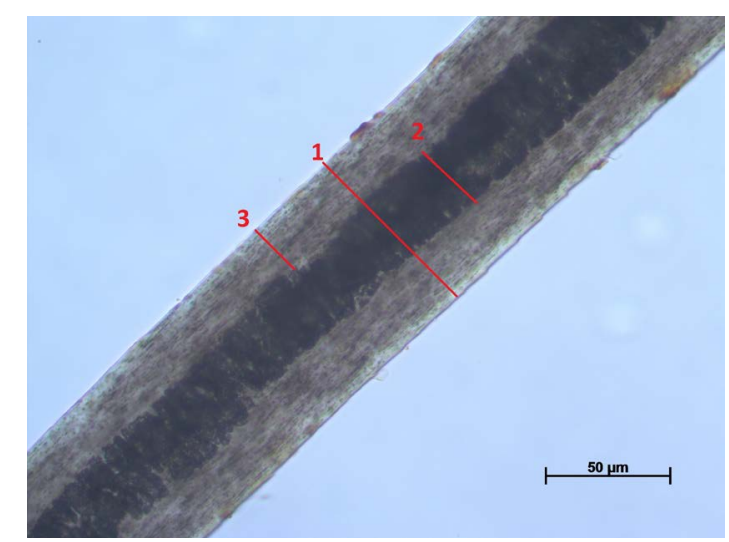

Figure 1. Optical microscopy hair of a brown howler monkey (Alouatta guariba). 1-overall diameter; 2 -medulla diameter; 3 -cuticle overall distance diameter/medulla diameter. $400 \times$. 
diameter, total hair diameter and medulla diameter/total diameter ratio (aka the medulla ratio or medulla index). The lengths of the hairs were obtained with a ruler. The data was tabulated in MS Excel 2007 and the descriptive statistics analysis was performed with the software GraphPad Prism7 version for windows, La Jolla California ${ }^{\circledR}$, USA.

\section{Results}

The hair samples were analyzed and each species specified after evaluated regarding their extinction risk according to IUCN Red List (Table 1). Figures 2-14 show images of the hairs for both the internal features and scale impressions.

Each species sample was measured according to Table 2 showing the parameters: hair length, medulla diameter, and overall hair diameter and medulla/overall

Table 1. Classification about the risk of extinction and population of each species sample hair.

\begin{tabular}{cccc}
\hline Scientific name & Common name & Risk of extinction & Population \\
\hline Alouatta guariba & Brown Howler Monkey & Least concern & Decreasing \\
Ozotoceros bezoarticus & Pampas deer & Near threatened & Decreasing \\
Sylvilagus brasiliensis & Forest Rabbit & Least concern & Unknown \\
Panthera onca & Jaguar & Near threatened & Decreasing \\
Didelphis albiventris & White-eared Opossum & Least concern & Stable \\
Puma concolor & Cougar & Least concern & Decreasing \\
Myrmecophaga & Giant Anteater & Vulnerable & Decreasing \\
tridactyla & Northern Tiger Cat & Vulnerable & Decreasing \\
Deopardus tigrinus & Black Agouti & Least concern & Stable \\
\hline
\end{tabular}

a. Sample of a according to IUCN Red List [2].

Table 2. Complete data from each animal/species measured from the software ImageJ.

\begin{tabular}{ccccc}
\hline Species & Hair Length $(\mathrm{cm})$ & $\begin{array}{c}\text { Medulla Diameter } \\
(\mu \mathrm{m})\end{array}$ & $\begin{array}{c}\text { Overall Diameter } \\
(\mu \mathrm{m})\end{array}$ & $\begin{array}{c}\text { Ratio Overall } \\
\text { Diameter/Medulla }\end{array}$ \\
\hline $\begin{array}{c}\text { Brown Howler } \\
\text { Monkey }\end{array}$ & 4.0 & 28.369 & 72.057 & 2.540 \\
Pampas deer & 6.3 & 90.438 & 131.307 & 1.452 \\
Forest Rabbit & 3.0 & 39.084 & 79.035 & 2.022 \\
$\quad$ Jaguar & 0.7 & 57.714 & 82.342 & 1.427 \\
White-eared & 5.5 & 59.516 & 114.575 & 1.925 \\
Opossum & 2.3 & 26.625 & 47.814 & 1.796 \\
Cougar & 3.0 & 82.989 & 251.595 & 3.032 \\
Giant Anteater & 1.8 & 58.417 & 69.153 & 1.183782 \\
Northern Tiger Cat & 2.2 & 93.505 & 124.240 & 1.328699 \\
Cutia & & & &
\end{tabular}




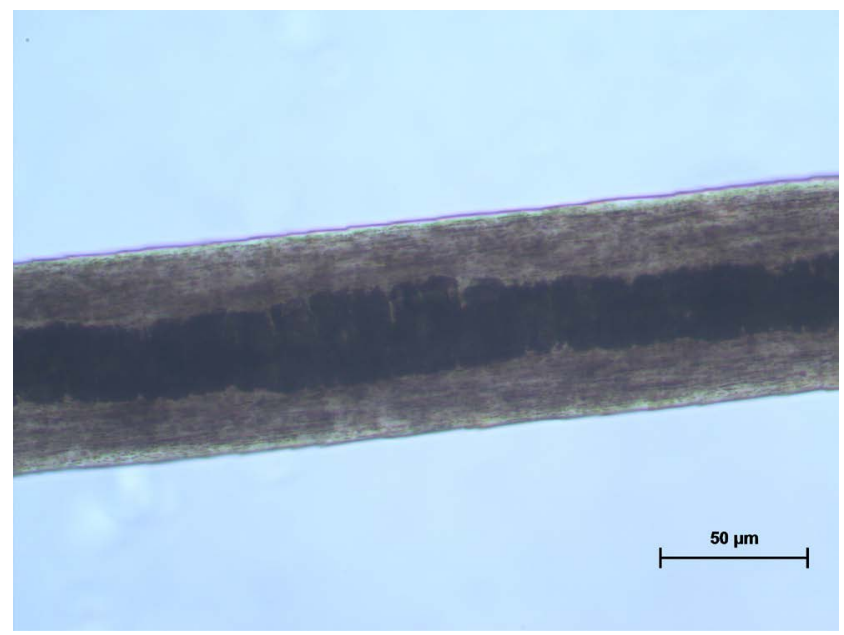

Figure 2. Optical microscopy of a brown howler monkey (Alouatta guariba) medulla hair. $400 \times$.

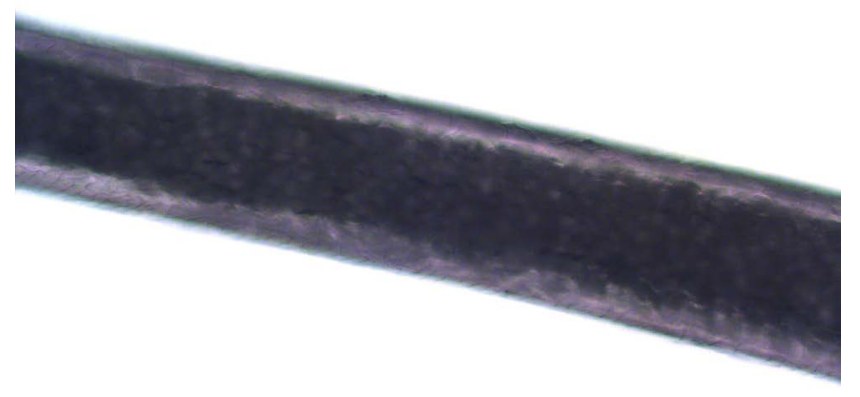

$\underline{50 \mu \mathrm{m}}$

Figure 3. Optical microscopy of a Pampas deer (Ozotoceros bezoarticus) medulla hair. 200x.

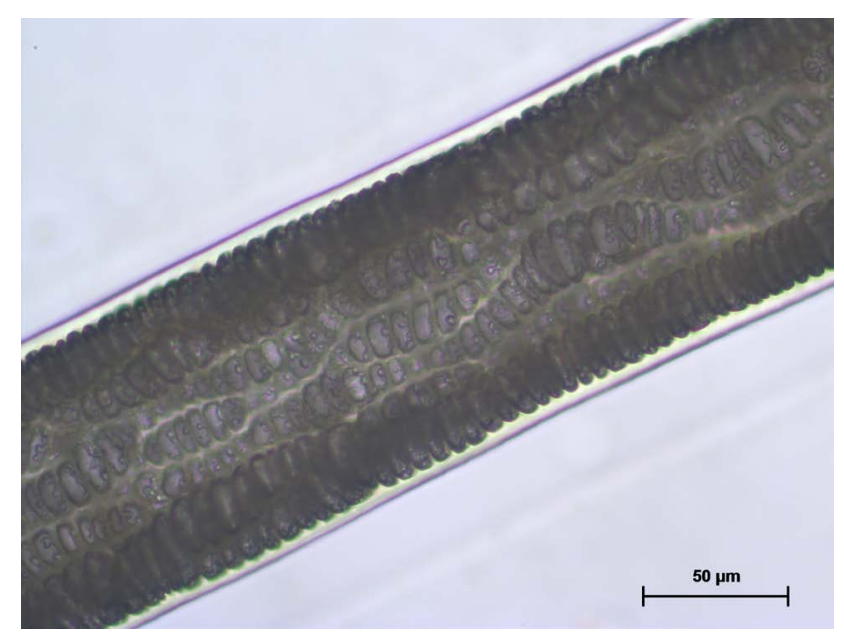

Figure 4. Optical microscopy of a forest rabbit (Sylvilagus brasiliensis) medulla hair. $400 \times$. 

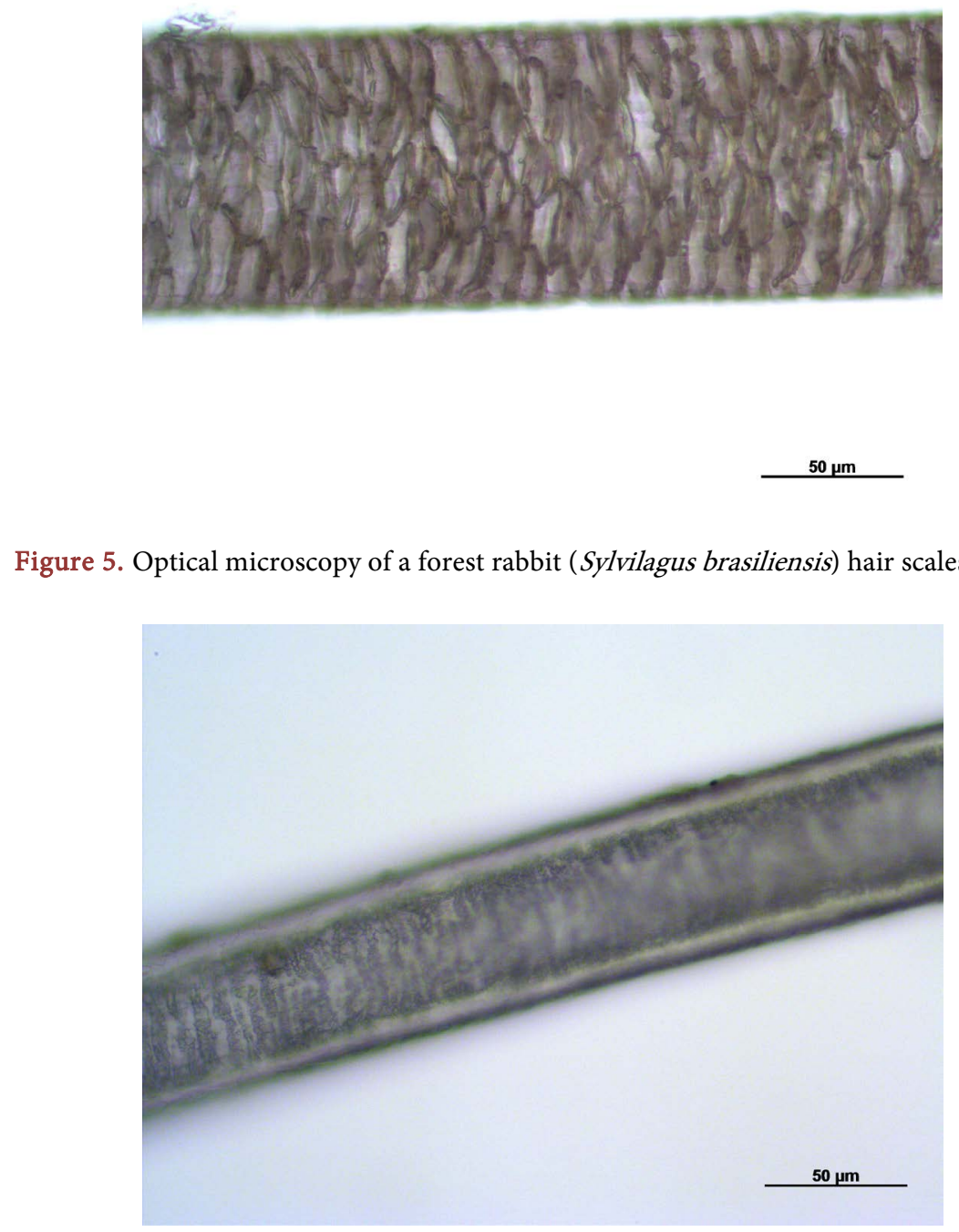

Figure 6. Optical microscopy of a Cougar (Puma concolor) medulla hair. 400×.

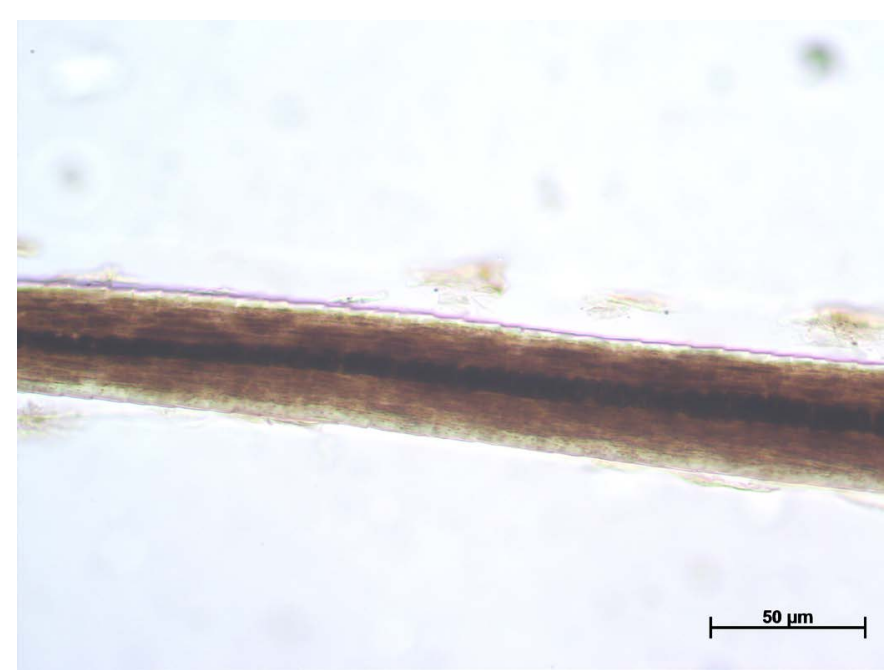

Figure 7. Optical microscopy of a Jaguar (Panthera onca) medulla hair. 400×. 


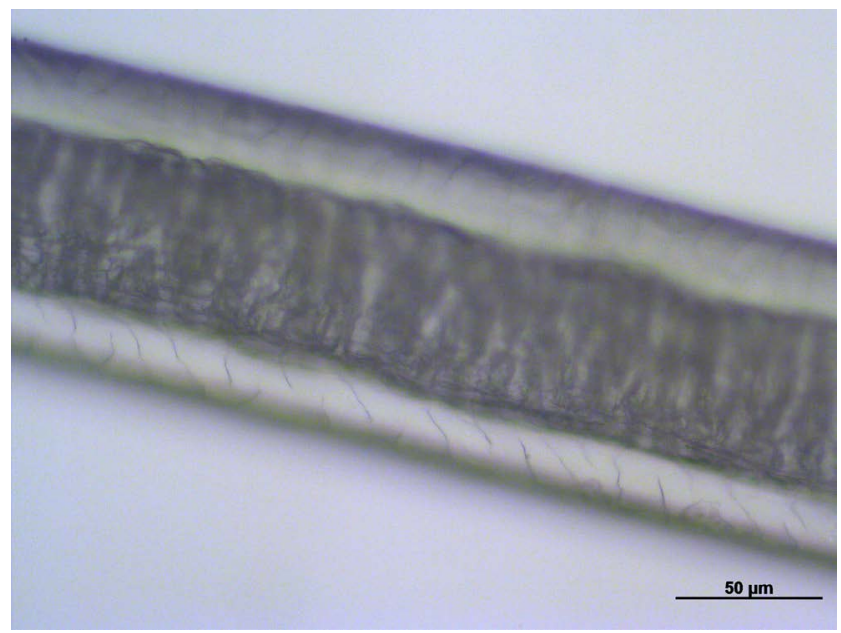

Figure 8. Optical microscopy of a White-eared Opossum (Didelphis albiventris) medulla and hair scales. $400 \times$.

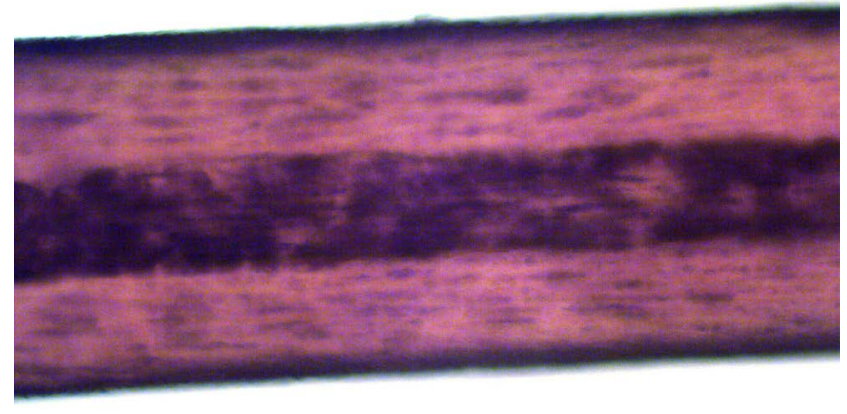

$\underline{50 \mu \mathrm{m}}$

Figure 9. Optical microscopy of a Giant Anteater (Myrmecophaga tridactyla) medulla hair. $200 \times$.

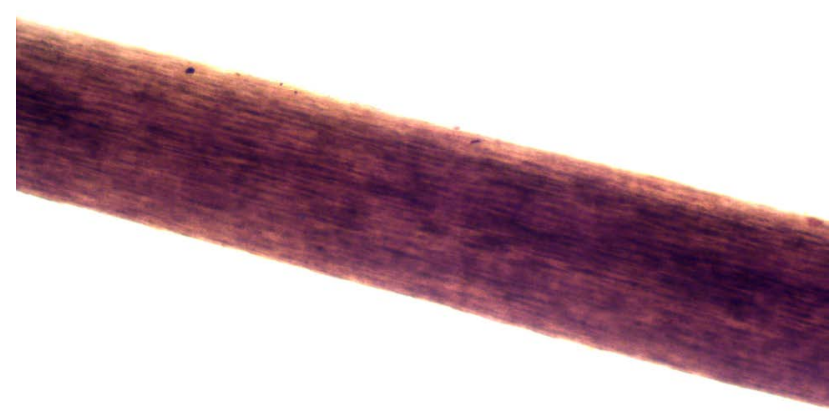

$\stackrel{50 \mu m}{\longmapsto}$

Figure 10. Optical microscopy of a Giant Anteater (Myrmecophaga tridactyla) hair scales. $100 \times$. 
$50 \mu \mathrm{m}$

Figure 11. Optical microscopy banded hair of a Northern Tiger cat (Leopardus tigrinus), showing scales and pigment. $200 \times$.

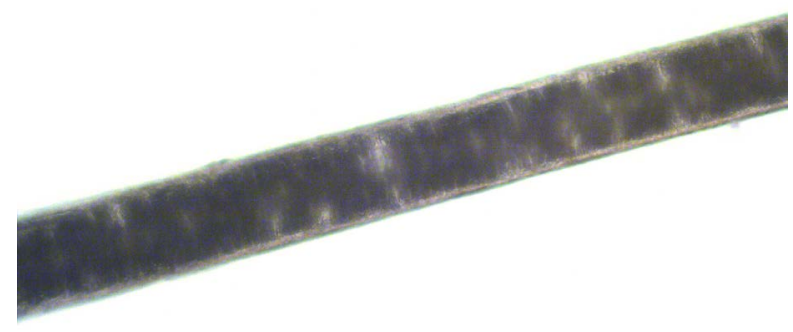

$\underline{50 \mu \mathrm{m}}$

Figure 12. Optical microscopy of a Northern Tiger cat (Leopardus tigrinus) medulla hair. 200x.

$\stackrel{50 \mu m}{\longmapsto}$

Figure 13. Optical microscopy of a Black agouti (Dasyprocta fuliginosa) hair scales with pigment. $100 \times$.

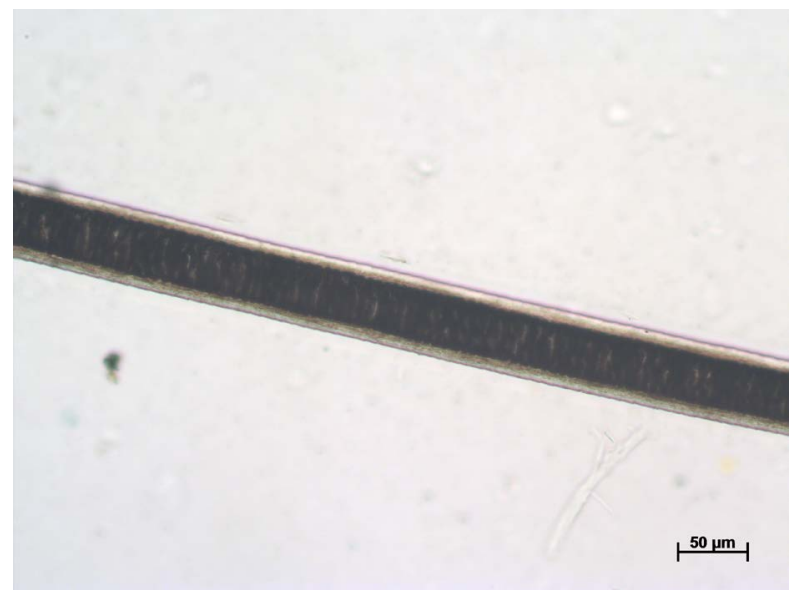

Figure 14. Optical microscopy of a Black agouti (Dasyprocta fuliginosa) medulla hair. $100 \times$. 
diameter ratio. These characteristics of hair morphometry show the particularity of each species.

The descriptive statistics analysis of the overall length of the hairs between species had an average of $3.2 \pm 1.79 \mathrm{~mm}$ and a non-parametric distribution, also on Wilcoxon analysis statistics significance was obtained $(P<0.05)$. Other remaining parameters have been non-parametric distribution and the Wilcoxon test for comparison between each specie covering all others measurements (medulla diameter, overall hair diameter, ratio overall diameter/medulla) statistics significance was obtained $(P<0.05)$.

\section{Discussion and Conclusion}

According to these analysis results, it is possible to infer that there is a difference between the measurements made in the hair samples of different species. This is exhibited by statistics analysis from the comparison among each species measurements. Besides the perceptible divergence of values, it is possible to highlight a great difference at the morphology of the hairs [11] [13] [19].

The photographed images used for measurement are clear and the measurements were easily performed, it is possible to note the distinction between the hairs. The technique reported in this study is simple, easy and cheap and can contribute effectively to several sectors, purposing the preservation of the national fauna and veterinary practice in the forensic area [6] [18] [20].

The preparation of the material began with the retrieval of hairs of the species to be analyzed. Correctly, multiples samples from more than one animal of each species are required to identify intra and inter-variation. To reduce contamination, a dedicated area reserved for this particular research was used, with the use of lab coat and personal protective equipment (PPE). In order to avoid sample mix-up, each species was analyzed individually and separately from the others. The labeling and packaging of the samples are important for the adequate preservation of the chain of custody and integrity of the sample; hairs were packaged in paper envelopes inserted in plastic bags of adequate size for each type of hair [2] [15].

The comparison of the morphology of the hairs could be a trial method and resulted in another examination to confirm the species, although genetics is the "gold standard" for the identification, it is a complementary technique that helps to direct the analysis and to increase the sensitivity of the expert report [16] [17].

Futures works are required to quantify the variation that may be present in hairs from different body areas of these species and in different individuals from the same species. This will enable the interpretation of this analysis to be more accurate for the law courts. Further hair characteristics should be explored for their ability to differentiate between these species and closely related ones for greater discrimination [1] [5] [7] [11].

The images obtained and the quantitative measurements contribute to the identification of these previously undocumented species through the morpholo- 
gy of the hairs and the statistics analysis corroborates in favor of validating the technique. This study ultimately aims to aid the identification of animals in a simpler, faster and effective way to benefit the daily analysis of the practitioners working in veterinary forensics. This study contributes to the ongoing research for the preservation of threatened Brazilian's fauna.

\section{Acknowledgements}

Coordination for the Improvement of Higher Education Personnel (CAPES)-Pró Forenses 25/2014 Process 23038.006841/2014-11. Mata Ciliar Association, NGO, Jundiaí, São Paulo, Brazil.

\section{References}

[1] Galetti, M., Moleón, M., Jordano, P., Pires, M.M., Guimarães, P.R., Pape, T., et al. (2017) Ecological and Evolutionary Legacy of Megafauna Extinctions. Biological Reviews, 93, No. 2. https://doi.org/10.1111/brv.12374

[2] Vié, J.C., Hilton-Taylor, C. and Stuart, S.N. (Eds.) (2009) Wildlife in a Changing World: An Analysis of the 2008 IUCN Red List of Threatened Species. IUCN, Gland.

[3] Daszak, P. (2008) Emerging Infectious Diseases of Wildlife-Threats to Biodiversity and Human Health. Science, 287, 443-449.

http://www.sciencemag.org/cgi/doi/10.1126/science.287.5452.443 https://doi.org/10.1126/science.287.5452.443

[4] Reis, S.T.J., de Lavor, L.M.S., Sant'Ana, L.V., Tremori, T.M., Gonzalez, V.A.T. and Brügger, P. (2016) Retrospective Study of Expert Examination Performed by the Brazilian Federal Police in Investigations of Wildlife Crimes, 2013-2014. Brazilian Journal of Forensic Sciences, Medical Law and Bioethics, 5, 198-214. https://doi.org/10.17063/bjfs5(2)y2016198

[5] Tremori, T.M. and Rocha, N.S. (2013) The Examination of the Corpus Delicti in Veterinary Expertise. Journal of Continuing Education in Animal Science of $C R M V-S P 2,11,30-35$.

[6] Munro, R. and Munro, H.M.C. (2013) Some Challenges in Forensic Veterinary Pathology: A Review. Journal of Comparative Pathology, 149, 57-73.

https://doi.org/10.1016/j.jcpa.2012.10.001

[7] Gerdin, J.A. and McDonough, S.P. (2013) Forensic Pathology of Companion Animal Abuse and Neglect. Veterinary Pathology, 50, 994-1006.

http://journals.sagepub.com/doi/10.1177/0300985813488895 https://doi.org/10.1177/0300985813488895

[8] Gupta, S.K., Bhagavatula, J., Thangaraj, K. and Singh, L. (2011) Establishing the Identity of the Massacred Tigress in a Case of Wildlife Crime. Forensic Science International: Genetics, 5, 74-75. https://doi.org/10.1016/j.fsigen.2010.05.004

[9] Alacs, E.A., Georges, A., FitzSimmons, N.N. and Robertson, J. (2010) DNA Detective: A Review of Molecular Approaches to Wildlife Forensics. Forensic Science, Medicine and Pathology, 6, 180-194. https://doi.org/10.1007/s12024-009-9131-7

[10] Dawnay, N., Ogden, R., McEwing, R., Carvalho, G.R. and Thorpe, R.S. (2007) Validation of the Barcoding Gene COI for Use in Forensic Genetic Species Identification. Forensic Science International, 173, 1-6. https://doi.org/10.1016/j.forsciint.2006.09.013 
[11] de Miranda, G., Rodrigues, F. and Paglia, A. (2014) Guide to Identification of Brazilian Mammal's Hair. Forensic Sciences, 108 p.

http://www.researchgate.net/profile/Guilherme_Miranda2/publication/266908770_ Guia_de_Identificao_de_Pelos_de_Mamferos_Brasileiros/links/5450c45a0cf201441 e93cfa8.pdf

[12] Tridico, S.R., Houck, M.M., Kirkbride, K.P., Smith, M.E. and Yates, B.C. (2014) Morphological Identification of Animal Hairs: Myths and Misconceptions, Possibilities and Pitfalls. Forensic Science International, 238, 101-107. https://doi.org/10.1016/j.forsciint.2014.02.023

[13] Sato, H. (2003) Preliminary Study of Hair Form of Japanese Head Hairs Using Image Analysis. Forensic Science International, 131, 202-208. https://doi.org/10.1016/S0379-0738(02)00450-4

[14] Pozebon, D., Scheffler, G.L. and Dressler, V.L. (2017) Elemental Hair Analysis: A Review of Procedures and Applications. Analytica Chimica Acta, 992, 1-23.

[15] Merigueti, Y.F.F.B., Santarém, V.A., Ramires, L.M., da Silveira Batista, A., da Costa Beserra, L.V., Nuci, A.L., et al. (2017) Protective and Risk Factors Associated with the Presence of Toxocara spp. Eggs in Dog Hair. Veterinary Parasitology, 244, 39-43. https://doi.org/10.1016/j.vetpar.2017.07.020

[16] Bellis, C., Ashton, K.J., Freney, L., Blair, B. and Griffiths, L.R. (2003) A Molecular Genetic Approach for Forensic Animal Species Identification. Forensic Science International, 134, 99-108. https://doi.org/10.1016/S0379-0738(03)00128-2

[17] Khedkar, G.D., Abhayankar, S.B., Nalage, D., Ahmed, S.N. and Khedkar, C.D. (2014) DNA Barcode Based Wildlife Forensics for Resolving the Origin of Claw Samples Using a Novel Primer Cocktail. Mitochondrial DNA, 27, 3932-3935. http://www.tandfonline.com/doi/full/10.3109/19401736.2014.987270

[18] Yates, B.C., Espinoza, E.O. and Baker, B.W. (2010) Forensic Species Identification of Elephant (Elephantidae) and Giraffe (Giraffidae) Tail Hair Using Light Microscopy. Forensic Science, Medicine, and Pathology, 6, 165-171. https://doi.org/10.1007/s12024-010-9169-6

[19] Sato, H., Matsuda, H., Kubota, S. and Kawano, K. (2006) Statistical Comparison of Dog and Cat Guard Hairs Using Numerical Morphology. Forensic Science International, 158, 94-103. https://doi.org/10.1016/j.forsciint.2005.04.041

[20] Sato, I., Nakaki, S., Murata, K., Takeshita, H. and Mukai, T. (2010) Forensic Hair Analysis to Identify Animal Species on a Case of Pet Animal Abuse. International Journal of Legal Medicine, 124, 249-256. https://doi.org/10.1007/s00414-009-0383-2 